\title{
A dificil tarefa de informar em meio a uma pandemia
}

I ${ }^{1}$ Kenneth Rochel de Camargo Jr., ${ }^{2}$ Claudia Medina Coeli I

Instituto de Medicina Social, Universidade do Estado do Rio de Janeiro. Rio de Janeiro-RJ, Brasil (kenneth@uerj.br).
ORCID: 0000-0003-3606-5853
2 Universidade Federal do Rio de Janeiro. Rio de Janeiro-RJ, Brasil (coelicm@gmail.com). ORCID: 0000-0003-1757-3940
Recebido em: 20/04/2020
Aprovado em: 23/04/2020
Revisado em: 27/04/2020

DOI: http://dx.doi.org/10.1590/S0103-73312020300203

O surgimento de uma nova doença transmitida por um vírus com importante capacidade de propagação e letalidade relativamente alta criou, compreensivelmente, alarme em todo o mundo, bem como as reaçóes usuais de negar o problema.

As respostas à pandemia incluem um verdadeiro maremoto de informaçóes, embasadas em fatos e pesquisas, mas também fantasiosas ou deliberadamente distorcidas, criando um problema para quem tenta se orientar e tomar decisóes sobre como enfrentar o que se apresenta. A crescente importância de meios de comunicação mediados pela internet aumentou a escala dessas dificuldades, além de fomentar a animosidade entre diversos grupos, com a utilização de informaçóes manipuladas como arma política.

Dados epidemiológicos, sobretudo, são compulsivamente buscados, na tentativa de compreender o que os mesmos dizem. O problema é que, como as rosas de Cartola e as estrelas de Olavo Bilac, dados não falam, sendo sempre necessária a intervenção de agentes humanos para que ganhem sentido. No clima de polarizaçáo observado mundialmente, a suposta objetividade dos dados tem sido posta constantemente em questáo por seu recrutamento a serviço de teses diametralmente opostas.

$\mathrm{Na}$ ausência de soluçóes biomédicas estritas, isto é, vacinas ou medicamentos eficazes, a resposta possível para tentar controlar a propagação da pandemia está na adoção de medidas que restrinjam ao máximo o contato interpessoal, em especial 
o confinamento de pessoal não essencial em suas casas, o que evidentemente contraria interesses econômicos. Isto gerou um verdadeiro campo de batalha, claramente dividido segundo linhas políticas. Apesar de um conjunto bastante convincente de evidências ter mostrado a eficácia de tais medidas (ANDERSON et al., 2020; HELLEWELL et al., 2020; LEE; CHIEW; KHONG, 2020; MAIER; BROCKMANN, 2020; NIUD; XU, 2020; PARODI; LIU, 2020; SALZBERGER; GLÜCK; EHRENSTEIN, 2020; TANG et al., 2020), e de economistas apontarem para iniciativas que podem minorar seus impactos e acelerar a recuperação econômica uma vez superada a pandemia (BALDWIN; DI MAURO, 2020), em vários países movimentos conservadores e certos empresários agem politicamente contra sua implementação e/ou manutenção. As estratégias adotadas por tais grupos frequentemente envolvem variaçóes de negacionismo (“denialism”), definido como "emprego de argumentos retóricos para dar a aparência de debate legítimo onde nenhum existe, uma abordagem que tem como objetivo último rejeitar uma proposição sobre a qual existe consenso científico” (DIETHELM; MCKEE, 2009).

Ainda segundo estes últimos autores, os processos de negacionismo apresentam cinco características, todas observadas ao longo dos últimos meses nas discussôes públicas sobre a pandemia: 1) identificação de conspiraçôes; 2) uso de falsos experts; 3) seletividade, focalizando em artigos isolados que contrariam o consenso científico (“cherry-picking”); 4) criação de expectativas impossíveis para a pesquisa; e 5) uso de deturpaçóes ou falácias lógicas.

Com relação à disseminação de dados epidemiológicos, tem-se visto claramente a proliferação de supostos experts, a seletividade na utilização de fontes e nas suas interpretaçôes, e muitas deturpaçôes. Um exemplo foi a utilização das análises do site EuroMOMO (European monitoring of excess mortality for public health action) para minimizar os impactos da Covid-19. Este site é fruto de um projeto colaborativo de pesquisadores europeus criado em 2008 para monitorar as taxas de mortalidade na Europa, para subsidiar açóes de saúde pública. $O$ site apresenta as tendências das taxas de mortalidade para o continente e seus países, utilizando ferramentas estatísticas para identificar a ocorrência de aumentos relevantes nas mesmas. Observamos a circulação de materiais nos meios de comunicação mediados pela internet que se apoiavam nos dados desse site até o final de março para negar o impacto em termos de mortalidade da Covid-19, uma vez que a estatística não apresentava, então, um aumento de mortalidade acima do esperado. Os supostos experts responsáveis por 
tais materiais, ainda que com alguma qualificação em saúde, não eram estatísticos ou epidemiologistas, contudo.

O fato apresentado seletivamente ignorava que os dados se referiam ao conjunto do continente europeu, e com o número de óbitos naquele momento concentrado em poucos países ainda não se refletia no universo estudado. Ainda assim, a mesma página apresentava mapas com codificação de cores que mostrava de forma inequívoca um excesso de mortalidade na Itália, por exemplo. De todo modo, atualização feita pouco depois já afirmava que "[a]s estimativas de mortalidade combinada da rede EuroMOMO continuam mostrando um aumento acentuado no excesso de mortalidade por todas as causas nos países europeus participantes, coincidindo com a atual pandemia global do Covid-19.” (EuroMOMO, 2020).

Adicionalmente, a estratégia denominada de "isolamento social" não é devida apenas aos óbitos pela doença, mas pela sobrecarga que a mesma representa para serviços de saúde. O número de pacientes graves que necessitam de leitos em Unidades de Tratamento Intensivo é consideravelmente maior do que o número de óbitos, e o aumento súbito na demanda por este tipo de curso pode levar sistemas inteiros ao colapso, criando dificuldades não apenas para pacientes com Covid-19, mas para qualquer outro agravo de saúde que necessite do mesmo recurso, daí a estratégia conhecida como "achatar a curva".

De todo modo, há uma enorme dificuldade em formar um quadro coerente e estável em se tratando de uma pandemia em pleno desenvolvimento; como lembram Collins e Evans, a política tem uma velocidade muito maior do que a ciência (COLLINS; EVANS, 2017), e isso é tanto ou mais verdade em termos de uma discussão pública. Vejam-se por exemplo as valentes tentativas de produzir modelos para a progressão da epidemia; dado o número de incertezas, qualquer modelagem será inerentemente frágil, ainda que necessária, e embora isso seja claro para epidemiólogos e estatísticos, não tem necessariamente a mesma transparência para o conjunto da população. As recomendaçôes mudam ao longo do tempo face às novas realidades que se apresentam, e a tomada de decisão se dá em ambiente de alta incerteza. Um exemplo claro é sobre a questão do uso ou não de máscaras, que teve recomendaçóes da OMS com mudanças expressivas ao longo do tempo. A apresentação de múltiplos indicadores sem o devido esclarecimento de seu significado pode criar mais confusão do que esclarecimento, além de poder potencialmente se prestar a distorçôes deliberadas do que representam. Sendo assim, é importante 
buscar formas de prover informação que sejam inteligíveis mesmo para não iniciados; mesmo pesquisadores devem procurar formas de interação dirigidas a públicos gerais, até mesmo para manter a legitimidade da própria ciência (CAMARGO JR, 2018).

Um bom exemplo deste esforço é a iniciativa de pesquisadores de São Paulo, que criaram um site (Observatório Covid-19 BR) ${ }^{1}$ que apresenta informaçôes atualizadas sobre a Covid-19 no município de modo acessível. Além de gráficos ilustrativos, o site traz textos curtos com explicaçôes sobre os gráficos, o processo de obtenção dos dados e seu processamento, bem como o significado prático do que é apresentado. Ainda que limitada pela desigualdade no acesso à internet, é um passo no sentido correto. A democratização do acesso à informação, além de um direito dos cidadãos, é necessária para o estabelecimento de políticas que possam dar o combate adequado à pandemia e suas implicaçóes econômicas.

\section{Referências}

ANDERSON, R. M. et al. How will country-based mitigation measures influence the course of the COVID-19 epidemic? The Lancet, v. 395, n. 10228, p. 931-934, 2020.

BALDWIN, R.; DI MAURO, B. W. Mitigating the COVID economic crisis: Act fast and do whatever it takes. VoxEu. org, CEPR, 2020. Disponível em: https://voxeu.org/content/ mitigating-covid-economic-crisis-act-fast-and-do-whatever-it-takes

CAMARGO JR, K. R. DE. Para defender a ciência, é necessário torná-la acessivel, inteligivel e significativa. [s.1.] SciELO Public Health, 2018. https://doi.org/10.1590/s0103-73312018280202

COLLINS, H.; EVANS, R. Why democracies need science. New York: John Wiley \& Sons, 2017.

DIETHELM, P.; MCKEE, M. Denialism: what is it and how should scientists respond? The European Journal of Public Health, v. 19, n. 1, p. 2-4, 2009.

EuroMOMO. European monitoring of excess mortality for public health action. Disponível em: <https://www.euromomo.eu/> Acessado em: 20 abr 2020.

HELLEWELL, J. et al. Feasibility of controlling COVID-19 outbreaks by isolation of cases and contacts. The Lancet Global Health, 2020. DOI: https://doi.org/10.1016/S2214109X(20)30074-7

LEE, V. J.; CHIEW, C. J.; KHONG, W. X. Interrupting transmission of COVID-19: lessons from containment efforts in Singapore. Journal of Travel Medicine, 2020. Doi: 10.1093/jtm/ taaa039. [Epub ahead of print]

MAIER, B. F.; BROCKMANN, D. Effective containment explains subexponential growth in recent confirmed COVID-19 cases in China. Science, 2020. Doi: 10.1126/science.abb4557 
NIUD, Y.; XU, F. Deciphering the power of isolation in controlling COVID-19 outbreaks. The Lancet Global Health, v. 8, n. 4, p. e452-e453, 2020.

PARODI, S. M.; LIU, V. X. From Containment to Mitigation of COVID-19 in the US. $J A M A, 2020$.

SALZBERGER, B.; GLÜCK, T.; EHRENSTEIN, B. Successful containment of COVID-19: the WHO-Report on the COVID-19 outbreak in China. [s.1.] Springer, 2020. DOI: 10.1007/s15010020-01409-4

TANG, B. et al. The effectiveness of quarantine and isolation determine the trend of the COVID-19 epidemics in the final phase of the current outbreak in China. International Journal of Infectious Diseases, 2020. Disponível em: https://doi.org/10.1016/j.ijid.2020.03.018

\section{Nota}

${ }^{1}<$ https://covid19br.github.io/municipio_SP> Acesso em: 21 abr 2020. 